05

\title{
Модуляция магнитоупругой связи при ферромагнитном резонансе в пленках феррит-гранатов
}

\author{
() С.Н. Полулях, ${ }^{1}$ В.Н. Бержанский, ${ }^{1}$ Е.Ю. Семук, ${ }^{1}$ В.И. Белотелов, ${ }^{1-3}$ П.М. Ветошко, ${ }^{1,2,4}$ В.В. Попов, ${ }^{1}$ \\ А.Н. Шапошников, ${ }^{1}$ А.И. Чернов ${ }^{1,2}$ \\ ${ }^{1}$ Крымский федеральный университет им. В.И. Вернадского, \\ 295007 Симферополь, Россия \\ ${ }^{2}$ Российский квантовый центр, \\ 121205 Москва, Россия \\ ${ }^{3}$ Московский государственный университет им. М.В. Ломоносова, \\ 119991 Москва, Россия \\ ${ }^{4}$ Институт радиотехники и электроники им. В.А. Котельникова РАН, \\ 125009 Москва, Россия \\ e-mail: sergey.polulyakh@cfuv.ru
}

Поступило в Редакцию 21 октября 2020 г.

В окончательной редакции 14 января 2021 г.

Принято к публикации 1 февраля 2021 г.

Исследован низкополевой ферромагнитный резонанс в эпитаксиальных пленках ферритов-гранатов различного состава с анизотропией „легкая плоскость“. В спектрах ферромагнитного резонанса, полученных путем частотной развертки, для ряда образцов обнаружена модуляция интенсивности спектральной линии набором узких, шириной порядка $100 \mathrm{kHz}$, равноотстоящих друг от друга по частоте линий. Частотный интервал между линиями согласуется с резонансом стоячих мод поперечных упругих колебаний по толщине структуры пленка-подложка для образцов разной толщины. Глубина модуляции уменьшается с увеличением частоты, что обусловлено зависимостью магнитоупругой связи от частоты моды упругих колебаний. Для одних образцов глубина модуляции уменьшается монотонно, а других - осциллируя, что связано с сильным и слабым поверхностным закреплением спинов соответственно. Обсуждены влияние интерфейса пленка-подложка и гибридизация упругих и спиновых мод колебаний в условиях магнитоакустического резонанса.

Ключевые слова: ферромагнитный резонанс, магнитоупругие взаимодействия, эпитаксиальные пленки феррит-гранатов.

DOI: 10.21883/JTF.2021.07.50953.295-20

\section{Введение}

Магнитоупругие взаимодействия наиболее сильно проявляются в магнитных материалах. В частности, феррит-гранаты благодаря высокой добротности спиновых и упругих мод колебаний эффективно демонстрируют динамическое взаимодействие магнитной и упругой подсистем [1]. При совпадении частот и волновых векторов спиновой и упругой волн возникает магнитоакустический резонанс. В результате гибридизации колебаний появляются квазиупругие волны со скоростью, отличной от скорости упругой волны в среде [1-3]. Как правило, динамические магнитоупругие взаимодействия проявляются в экспериментах по ферромагнитному резонансу (ФМР) или в спин-волновых экспериментах и состоят в том, что прецессирующая намагниченность возбуждает упругие колебания $[4,5]$. Обратный эффект - возбуждение прецессии намагниченности с помощью поверхностных акустических волн наблюдался, например, в эпитаксиальных слоях $(\mathrm{Ga}, \mathrm{Mn})(\mathrm{As}, \mathrm{P})[6]$.

Наряду с ферримагнитными гранатами широкое распространение при исследовании магнитоупругих взаимо- действий получили слабые ферромагнетики - антиферромагнетики со скосом магнитных подрешеток. В этих материалах магнитоупругие взаимодействия оказываются намного сильнее дипольных вследствие малости вектора ферромагнетизма [7]. В антиферромагнитных материалах сильно выражены эффекты, связанные с нелинейными магнитоупругими взаимодействиями [8]. Кроме того, спин-волновая акустика в антиферромагнитных структурах позволяет рассматривать эти структуры как особый класс магнитоакустических метаматериалов [7].

Популярным объектом исследования магнитоупругих взаимодействий являются эпитаксиальные пленки феррит-гранатов (ЭПФГ). Упругие колебания, сформированные за счет магнитоупругих взаимодействий в магнитной пленке, распространяются в немагнитной подложке. Результат магнитоупругого взаимодействия наблюдается в виде модуляции спин-волновых спектров набором узких линий, соответствующих акустическому резонансу упругих мод колебаний по толщине структуры пленка-подложка $[4,5,9-11]$. Благодаря высокой добротности упругих колебаний экспериментально наблюдаются моды с номерами до нескольких сотен. 
Основные параметры образцов ЭПФГ

\begin{tabular}{c|c|c|c|c|c|c|c}
\hline Подложка & Состав пленки & $\begin{array}{c}\text { Толщина } \\
\text { пленки, } \mu \mathrm{m}\end{array}$ & $\begin{array}{c}\text { Толщина } \\
\text { подложки, } \mu \mathrm{m}\end{array}$ & $\Delta v, \mathrm{MHz}$ & $v_{C}, \mathrm{MHz}$ & $c_{F}^{(\text {res })}, \cdot 10^{3} \mathrm{~m} / \mathrm{s}$ & $c_{F}^{(\xi)}, \cdot 10^{3} \mathrm{~m} / \mathrm{s}$ \\
\hline \multirow{2}{*}{ ГГГ } & $(\mathrm{BiLu})_{3}(\mathrm{FeGa})_{5} \mathrm{O}_{12}$ & 12.0 & 450 & $3.860 \pm 0.005$ & $250 \pm 15$ & $3.45 \pm 0.15$ & $3.33 \pm 0.1$ \\
\cline { 3 - 8 } & 10.5 & 450 & $3.810 \pm 0.005$ & $297 \pm 15$ & $2.03 \pm 0.06$ & $2.96 \pm 0.1$ \\
\hline \multirow{2}{*}{$\begin{array}{c}\text { КМЦ } \\
\text { ГГГ }\end{array}$} & $(\mathrm{GdLu})_{3}(\mathrm{FeSc})_{5} \mathrm{O}_{12}$ & 9.9 & 500 & $3.610 \pm 0.005$ & $350 \pm 25$ & - & $3.47 \pm 0.1$ \\
\hline \multirow{3}{*}{ ГГГ } & $\mathrm{Tm}_{3}(\mathrm{FeSc})_{5} \mathrm{O}_{12}$ & 7.6 & 550 & $2.990 \pm 0.005$ & $400 \pm 25$ & $0.58 \pm 0.02$ & $3.04 \pm 0.1$ \\
\cline { 2 - 8 } & & 4.0 & 500 & $3.415 \pm 0.005$ & $730 \pm 50$ & $0.63 \pm 0.02$ & $2.92 \pm 0.1$ \\
\cline { 3 - 8 } & $(\mathrm{YLa})_{3}(\mathrm{FeScIn})_{5} \mathrm{O}_{12}$ & 2.7 & 550 & $3.190 \pm 0.005$ & $950 \pm 75$ & $1.01 \pm 0.10$ & $2.57 \pm 0.1$ \\
\cline { 3 - 8 } & & 1.5 & 550 & $3.220 \pm 0.005$ & $1500 \pm 150$ & $1.23 \pm 0.25$ & $2.25 \pm 0.2$
\end{tabular}

Возобновление интереса к таким явлениям в настоящее время обусловлено в частности тем, что благодаря наличию углового момента у поперечной упругой волны появляются возможности передачи углового момента через немагнитную подложку [12-15]. Исследования динамических магнитоупругих взаимодействий, как правило, проводятся в условиях неоднородной прецессии намагниченности в насыщающих магнитных полях, направленных перпендикулярно плоскости пленки.

С другой стороны, для магнитных сердечников датчиков магнитных полей используются ЭПФГ с планарным расположением намагниченности и слабой магнитной анизотропией в плоскости пленки [16,17]. В этом случае представляются интересными исследования ферромагнитного резонанса (ФМР) в слабых магнитных полях, лежащих в плоскости пленки [18].

В настоящей работе исследовались образцы легкоплоскостных ЭПФГ с различным катионным замещением. Спектры ФМР регистрировались в частотном диапазоне до $1.5 \mathrm{GHz}$ в слабых (до $150 \mathrm{Oe}$ ) магнитных полях, ориентированных в плоскости пленки. В отличие от широко распространенных ФМР-экспериментов в $X$-диапазоне электромагнитного излучения в наших экспериментах использовалась не полевая, а частотная развертка, и наши эксперименты можно рассматривать как низкополевой ФМР.

Для ряда образцов экспериментально обнаружена модуляция спектра ФМР набором узких равноотстоящих друг от друга по частоте спектральных линий. Период модуляции (расстояние по частоте между соседними линиями) увеличивается при уменьшении толщины подложки, а частотное положение линий хорошо согласуется с резонансом стоячих мод поперечных упругих колебаний по толщине образца. В условиях однородной прецессии намагниченности амплитуда модуляции зависит от частоты ФМР и модуляция исчезает при увеличении частоты выше некоторого критического значения $v_{C}$. Чем тоньше магнитная пленка, тем выше значение критической частоты $v_{C}$. В настоящей работе приводятся результаты исследований влияния толщины магнитной пленки на модуляцию низкополевых спектров ФМР при возбуждении поперечных упругих мод колебаний в ЭПФГ.

\section{1. Спектры ФМР}

Для проведения экспериментов использованы магнитные пленки катион-замещенных феррит-гранатов, состав которых приведен в таблице. Катионное замещение использовано для формирования магнитной анизотропии, укладывающей намагниченность в плоскость пленки. Синтез пленок осуществлялся методом жидкофазной эпитаксии из раствор-расплава. В качестве подложек использованы (111) пластины гадолиний-галлиевого граната $\mathrm{Gd}_{3} \mathrm{Ga}_{5} \mathrm{O}_{12}$ (ГГГ) и ГГГ, легированного кальцием, магнием и цирконием $(\mathrm{GdCa})_{3}(\mathrm{GaMgZr})_{5} \mathrm{O}_{12}$ (КМЦ ГГГ). Толщины подложек исследованных ЭПФГ также приведены таблице и лежали в пределах $500 \pm 50 \mu \mathrm{m}$.

Регистрация спектров ФМР осуществлялась с использованием векторного анализатора цепей $\mathrm{R} \& \mathrm{~S} \mathrm{ZNB}-20$ посредством регистрации частотной зависимости коэффициента пропускания $S_{21}$ специально изготовленной измерительной ячейки (рис. 1).

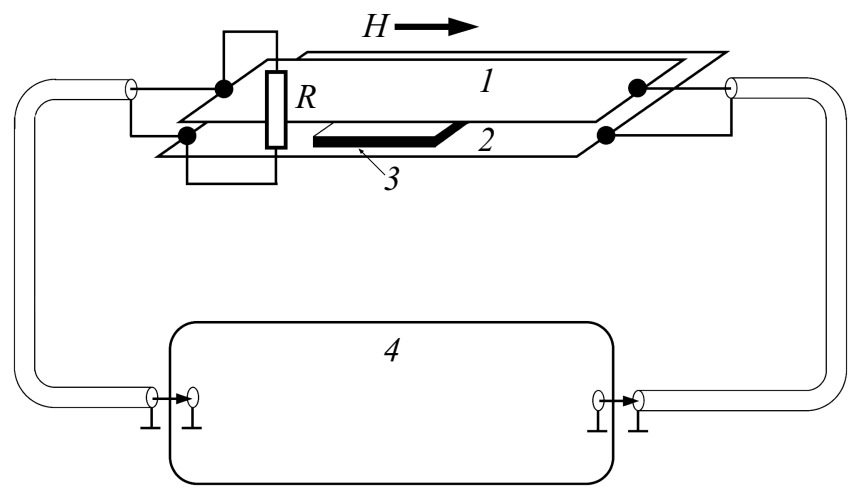

Рис. 1. Схема измерительного устройства: $1,2-$ металлические пластины, 3 - образец, 4 - векторный анализатор цепей R \& S ZNB-20. 
Измерительная ячейка представляла собой две плоскопараллельные металлические пластины, расположенные одна над другой. Размер пластины 1 составлял $10 \times 20 \mathrm{~mm}$, а пластина 2 была примерно на $5 \mathrm{~mm}$ шире. Для согласования с векторным анализатором цепей использовано активное сопротивление $R=50 \Omega$. В первом приближении измерительную ячейку можно рассматривать как несимметричную полосковую линию передач, в которой распространяются волны квази $T$-типа. Исследуемый образец помещался в зазор между пластинами, так, что переменное магнитное поле лежало в плоскости пленки. Постоянное магнитное поле $H$, создаваемое с помощью катушек Гельмгольца, также лежало в плоскости пленки перпендикулярно переменному. Для проведения экспериментов использовались образцы ЭПФГ, размер которых не превышал ширину пластины 1, благодаря чему переменное магнитное поле с хорошей степенью точности можно рассматривать как пространственно однородное.

Вначале регистрировалась частотная зависимость комплексного коэффициента пропускания $S_{21}$ измерительной ячейки без образца - калибровочный спектр. Затем регистрировалась зависимость $S_{21}$ от частоты ячейки с образцом, и из полученной зависимости вычитался калибровочный спектр. Вычитание проводилось раздельно для действительной и мнимой компонент $S_{21}$. Разностная, полученная путем вычитания калибровочного спектра частотная зависимость модуля $S_{21}$ ячейки с образцом представляет спектр образца.

В качестве примера на рис. 2 приведены спектры образца с толщиной пленки $10.5 \mu \mathrm{m}$. Спектр на рис. $2, a$ получен в поле $H=8.7 \mathrm{Oe}$, в котором образец не намагничен однородно, а находится в полидоменном состоянии. На фоне широкой линии ФМР виден набор узких, равноотстоящих по частоте линий с частотным интервалом $\Delta v \approx 3.81 \mathrm{MHz}$. При увеличении поля $(H=16.7 \mathrm{Oe}$ ) модуляция исчезает (рис. $2, b)$, а линия ФМР сужается, ввиду перехода пленки в насыщенное монодоменное состояние. Однако в поле $H=18.9 \mathrm{Oe}$ модуляция с тем же самым частотным интервалом $\Delta v$ появляется снова, а ширина линии ФМР соответствует насыщенному состоянию образца. В более сильных полях модуляция спектров ФМР исчезает вновь.

Модуляция спектров ФМР набором узких линий наблюдается для всех образцов, приведенных в таблице. В пределах ширины спектральной линии ФМР максимум амплитуды модуляции как в полидоменном, так и насыщенном состояниях наблюдается вблизи частоты ФМР (частота, соответствующая максимуму $S_{21}$ ). При увеличении частоты ФМР до некоторого критического значения $v_{C}$ модуляция исчезает. Для образцов $(\mathrm{BiLu})_{3}(\mathrm{FeGa})_{5} \mathrm{O}_{12}$ дальнейшее увеличение поля приводит к восстановлению модуляции с меньшей амплитудой, затем модуляция исчезает так, что затухание модуляции носит осциллирующий характер. Для остальных образцов модуляция исчезает при частоте ФМР $v_{C}$ и далее не восстанавливается. При этом чем тоньше
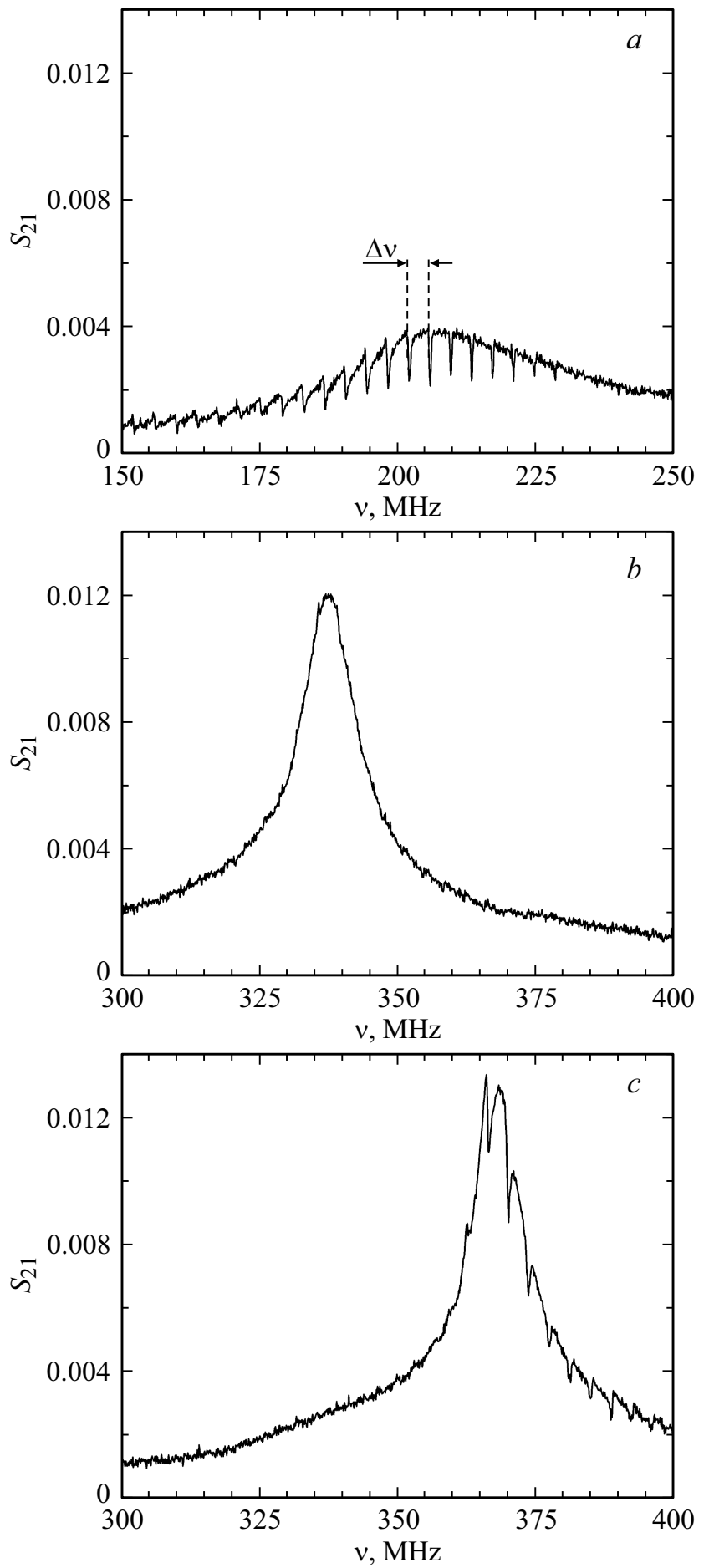

Рис. 2. Разностные частотные зависимости модуля комплексного коэффициента пропускания $S_{21}$ измерительной ячейки с образцом и пустой ячейки. Образец: ЭПФГ $(\mathrm{BiLu})_{3}(\mathrm{FeGa})_{5} \mathrm{O}_{12}$ толщиной $10.5 \mu \mathrm{m}$ во внешнем магнитном поле $H=8.7(a)$, $16.7(b)$ и 18.9 Oе $(c)$.

магнитная пленка, тем выше значение критической частоты $v_{C}$ (см. таблицу).

Период модуляции $\Delta v$ зависит, в первую очередь, от толщины подложки: чем толще подложка, тем меньше 
частотный интервал $\Delta v$ между линиями. По аналогии с работой [18] будем полагать, что прецессирующая намагниченность за счет магнитоупругих взаимодействий приводит к формированию сдвиговых волн, для которых система пленка-подложка выступает в качестве акустического резонатора. Резонанс возникает при условии, когда по толщине структуры пленка-подложка укладывается целое число длин полуволн упругих колебаний. Пренебрегая толщиной пленки, для частотного интервала имеем $\Delta v \approx c / 2 L$, где $c \approx 3.57 \cdot 10^{3} \mathrm{~m} / \mathrm{s}-$ скорость поперечной волны в ГГГ [4], $L-$ толщина подложки. То есть чем тоньше подложка, тем больше ожидаемый интервал $\Delta v$. Однако благодаря высокой добротности упругих колебаний в гранатах, величину $\Delta v$ удается определить с достаточно высокой точностью так, что ограничиться только толщиной подложки недостаточно. Следует учитывать полную толщину системы пленка-подложка.

\section{2. Упругий резонанс в системе пленка-подложка}

При анализе упругих колебаний в системе пленка-подложка будем рассматривать эту систему как сплошную среду, состоящую из двух слоев: магнитная пленка толщиной $h$ и подложка толщиной $L$. Для слоистой среды [19] упругие колебания в каждом из слоев описываются уравнением движения

$$
\frac{\partial^{2} u_{i}}{\partial t^{2}}=c_{i}^{2} \frac{\partial^{2} u_{i}}{\partial z^{2}} .
$$

Здесь $u_{i}-$ смещение в $i$-слое (либо пленка, либо подложка), $c_{i}-$ скорость упругой волны в соответствующем слое, $t-$ время, ось $z$ направлена вдоль нормали к пленке. Для магнитной пленки используется скорость упругой волны, модифицированная за счет магнитоупругих взаимодействий [1-3]. Поверхность ЭПФГ полагаем свободной, т. е. упругие напряжения на поверхности равны нулю, откуда $\partial u / \partial z=0$. На границе пленка-подложка используем условие непрерывности для упругого смещения и деформации. Тогда условие упругого резонанса структуры пленка-подложка можно записать либо для волнового числа в пленке $k_{F}$, либо для волнового числа в подложке $k_{G}$ (в условиях резонанса эти волновые числа оказываются линейно связанными):

$$
k_{F}=\frac{\pi n}{h+\xi^{-1} L}, \quad k_{G}=\frac{\pi n}{L+\xi h},
$$

где $n-$ номер моды, $\xi=c_{G} / c_{F}, c_{G}-$ скорость волны в подложке, $c_{F}-$ скорость волны в пленке. Условия (2) означают, что на „приведенной“ (с учетом различия скоростей волн в средах) толщине образца укладывается целое число длин полуволн упругих колебаний. При линейном законе дисперсии для частотного интервала между линиями упругих колебаний получаем

$$
\Delta v=\frac{c_{G}}{2(L+\xi h)}=\frac{c_{F}}{2\left(h+\xi^{-1} L\right)} .
$$

Если полагать известной скорость упругой волны в ГГГ подложке $c_{G} \approx 3.57 \cdot 10^{3} \mathrm{~m} / \mathrm{s}$ [4], то по частотному интервалу $\Delta v$ из (3) можно найти скорость упругой волны в ферритовой пленке

$$
c_{F}^{(\text {res })}=\frac{2 h \Delta v c_{G}}{c_{G}-2 L \Delta v} .
$$

Значения $c_{F}^{(\text {res })}$ для ЭПФГ с ГГГ подложкой, полученные из экспериментальных значений с помощью выражения (4), приведены в таблице. Для образца ЭПФГ с КМЦ-ГГГ подложкой получаются нефизические (отрицательные по величине) значения, что свидетельствует о том, что в легированном КМЦ-ГГГ скорость поперечной волны больше, чем в нелегированном ГГГ.

Оценки скорости упругой волны в магнитной пленке $c_{F}^{(\text {res })}$ для всех исследованных образцов дают значения, заметно меньшие, чем известная скорость поперечной волны в железо-иттриевом феррит-гранате $c_{Y I G} \approx$ $\approx 3.85 \cdot 10^{3} \mathrm{~m} / \mathrm{s}$ [4]. При этом для более тонких пленок реализуются меньшие значения $c_{F}^{(\text {res })}$. Это может свидетельствовать о том, что модель двуслойной среды не полностью отражает особенности резонанса в структуре пленка-подложка и необходимо учитывать, например, конечную толщину интерфейса пленка-подложка.

\section{3. Магнитоупругое возбуждение упругих волн}

Решения уравнений движения (1) позволяют построить распределение амплитуды смещения по толщине системы пленка-подложка (вдоль оси $z-$ оси, совпадающей с нормалью к пленке) для разных мод колебаний (рис. 3). В иллюстративных целях на рис. 3 приведена

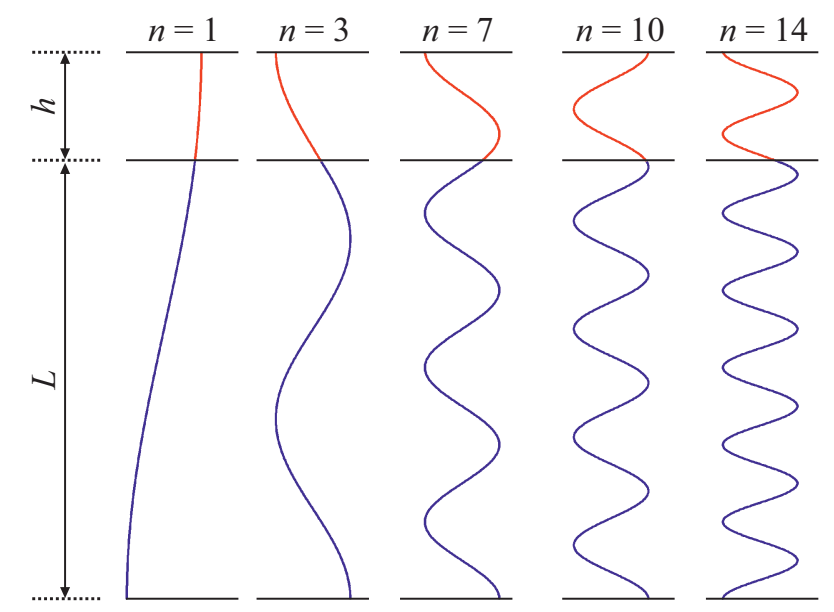

Рис. 3. Распределение упругого смещения вдоль нормали $z$ к плоскости ЭПФГ. $n$ - номер моды. 
ситуация, когда подложка толще пленки в 10 раз, что гораздо меньше реального соотношения. Для упругих мод с малыми номерами $\mathrm{n}$ величина смещения в пленке практически однородна по $z$. По мере увеличения номера моды неоднородность упругого смещения по $z$ растет и для мод с большими номерами по толщине магнитной пленки может поместиться несколько полуволн упругих колебаний.

Будем полагать, что в однородных переменном и постоянном магнитных полях амплитуда поперечной компоненты прецессирующей намагниченности $m$ пространственно однородна и не зависит от координаты Z вдоль нормали к образцу: $m(z)=m$ при $0 \leq z \leq h$, иначе $m(z)=0$. Однородное в пределах толщины пленки пространственное распределение намагниченности можно разложить в ряд Фурье по волновым векторам $k_{F}$. Тогда амплитуда гармоники с волновым вектором $k_{F}$ имеет вид

$$
F\left(k_{F}\right)=\frac{2 m}{k_{F}} \sin \frac{k_{F} h}{2} .
$$

В простейшем случае линейного закона дисперсии $2 \pi v=c_{F} k_{F}$ получаем

$$
F(v)=\frac{m c_{F}}{\pi v} \sin \frac{\pi v h}{c_{F}} .
$$

Для связанных колебаний магнитной и упругой подсистем образца по аналогии с работой [18] запишем систему уравнений:

$$
\left\{\begin{array}{l}
\left(\omega-\omega_{M}+i \gamma_{M}\right) m^{+}=\frac{\Omega}{2} \sum F\left(\omega_{k}\right) u_{k}^{+}+\chi h^{+}, \\
\sum_{k} \delta_{1 k}\left(\omega-\omega_{k}+i \gamma_{A}\right) u_{k}^{+}=\frac{\Omega m^{+}}{2} F\left(\omega_{1}\right), \\
\sum_{k} \delta_{N k}\left(\omega-\omega_{k}+i \gamma_{A}\right) u_{N}^{+}=\frac{\Omega m^{+}}{2} F\left(\omega_{N}\right) .
\end{array}\right.
$$

В этих уравнениях переменная $m^{+}=m_{x}+i m_{y}$ описывает амплитуду колебаний намагниченности, $i$ мнимая единица, $h^{+}$- амплитуда переменного магнитного поля, $\chi-$ магнитная восприимчивость. Магнитный осциллятор характеризуется резонансной частотой $\omega_{M}=2 \pi v_{M}$ и параметром затухания $\gamma_{M}$. Упругие моды рассматриваются как независимые друг от друга осцилляторы, каждый из которых связан с магнитным осциллятором. Колебания $k$-го упругого резонатора описываются комплексной амплитудой $u_{k}^{+}$, резонансной частотой $\omega_{k}=2 \pi v_{k}$ и одинаковым для всех осцилляторов параметром затухания $\gamma_{A} . N-$ общее число принимаемых во внимание осцилляторов.

Связь каждого из упругих осцилляторов с осциллятором магнитным определяется эффективным коэффициентом магнитоупругой связи $\Omega$. Однако в отличие от [18] здесь учтено неравномерное по толщине пленки распределение амплитуды упругих колебаний так, что степень связи пропорциональна амплитуде гармоники (6) на
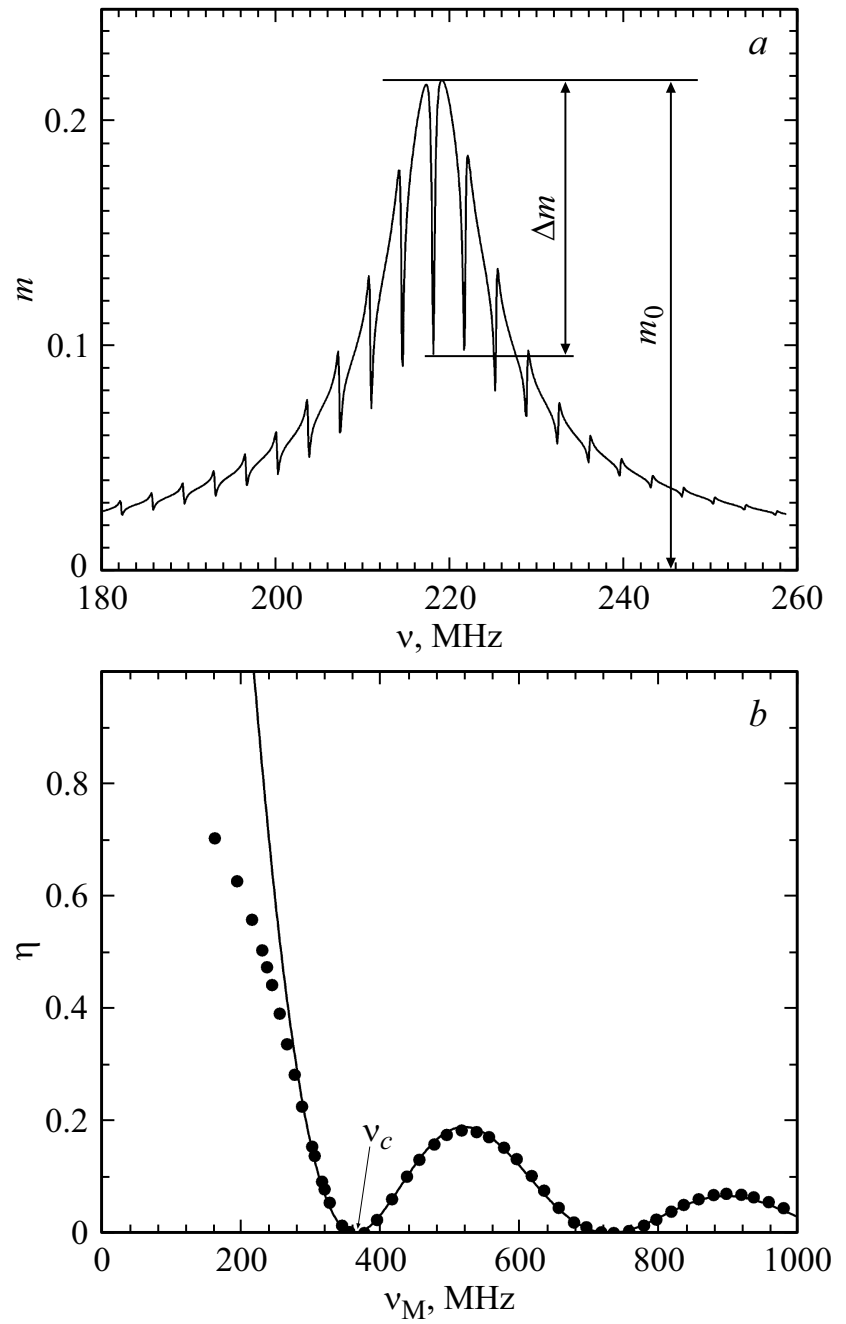

Рис. 4. Расчетная зависимость намагниченности $m$ от частоты $v(a)$ и расчетная зависимость глубины модуляции $\eta$ от частоты $Ф \mathrm{MP} v_{M}(b) ; \eta_{c}-$ критическая частота.

частоте $k$-й упругой моды $F\left(\omega_{k}\right)$. Имеет место частотная модуляция магнитоупругой связи.

Численное решение системы (7) позволяет получить зависимость комплексной амплитуды намагниченности от частоты. В результате проведенных расчетов обнаружено, что частотная зависимость модуля намагниченности $m=\sqrt{m_{x}^{2}+m_{y}^{2}}$ хорошо, с точностью до амплитудного множителя, описывает экспериментально наблюдаемую разностную зависимость модуля комплексного коэффициента пропускания $S_{21}$ от частоты. В качестве примера на рис. 4, $a$ приведена расчетная зависимость $m=m(v)$ при $\omega_{M} / 2 \pi=220 \mathrm{MHz}$ и $\gamma_{M} / 2 \pi=4.5 \mathrm{MHz}$. Использована $N=31$ акустическая мода с $\gamma_{A} / 2 \pi=0.1 \mathrm{MHz}$ и интервалом между резонансными частотами $\Delta v$, соответствующим пленке железоиттриевого граната толщиной $10 \mu \mathrm{m}$ на ГГГ подложке толщиной $500 \mu \mathrm{m}$. Частота ФМР и $\gamma_{M}$ выбраны так, чтобы проиллюстрировать основные экспериментально наблюдаемые особенности: максимум модуляции на- 
блюдается на частоте ФМР, а при расстройке между частотой ФМР и частотой упругой моды амплитуда модуляции падает. Кроме того, имеет место уменьшение амплитуды модуляции с ростом частоты.

В качестве параметра глубины модуляции выберем отношение величины „Провала“ $\Delta m$, обусловленного упругой модой на частоте ФМР $v_{M}$, к амплитуде $m_{0}$ на этой же частоте (рис. 4,a)

$$
\eta=\Delta m / m_{0} .
$$

На рис. 4, $b$ кружочками приведены значения глубины модуляции $\eta$, рассчитанные при различных значениях частоты ФМР $v_{M}$. Частота ФМР выбиралась равной частоте моды упругих колебаний. Сплошной линией на рис. $4, b$ приведена зависимость

$$
\eta\left(v_{M}\right)=\frac{\eta_{0}}{v_{M}^{2}} \sin ^{2} \frac{\pi v_{M} h}{c_{F}},
$$

где $c_{F}-$ скорость упругой волны в пленке ферритграната полагалась равной скорости упругой волны в железо-иттриевом гранате, а $\eta_{0}$ - подгоночный параметр. На рис. $4, b$ также обозначена критическая частота $v_{C}$ - частота, при которой амплитуда модуляции падает до нуля в первый раз.

Как следует из данных рис. $4, b$, теоретическая зависимость глубины модуляции от частоты ФМР хорошо описывается выражением (9) при $\eta<0.4$. Глубина модуляции пропорциональна квадрату амплитуды гармоники ввиду того, что этот параметр используется как для описания связи магнитного осциллятора с упругим, так и для обратной связи.

\section{4. Обсуждение результатов}

Для экспериментально зарегистрированных зависимостей $S_{21}=S_{21}(v)$ глубина модуляции $\eta$ определяется подобно (8), как отношение глубины провала к величине модуля коэффициента пропускания $S_{21}$ на частоте ФМР. В эксперименте частота ФМР определяется величиной постоянного магнитного поля, лежащего в плоскости пленки. Частотная зависимость глубины модуляции $\eta$, полученная для ЭПФГ толщиной $10.5 \mu \mathrm{m}$, приведена кружочками на рис. 5, $a$. Сплошная линия на этом рисунке получена с помощью (9) при $c_{F}=2.96 \cdot 10^{3} \mathrm{~m} / \mathrm{s}$. Из данных, приведенных на рис. 5, $a$, следует, что для достаточно толстой $h \approx 10.5 \mu \mathrm{m}$ пленки распределение переменной намагниченности вдоль нормали к пленке можно в первом приближении считать однородным. Подобная ситуация имеет место и для пленки толщиной $12 \mu \mathrm{m}$.

Однако для остальных исследованных образцов зависимость $\eta=\eta\left(v_{M}\right)$ имеет вид, подобный зависимости, полученной для образца толщиной $7.6 \mu \mathrm{m}$ и приведенной кружочками на рис. 5, $b$. В этом случае с ростом частоты глубина модуляции монотонно падает до нуля и больше не восстанавливается. Такое поведение
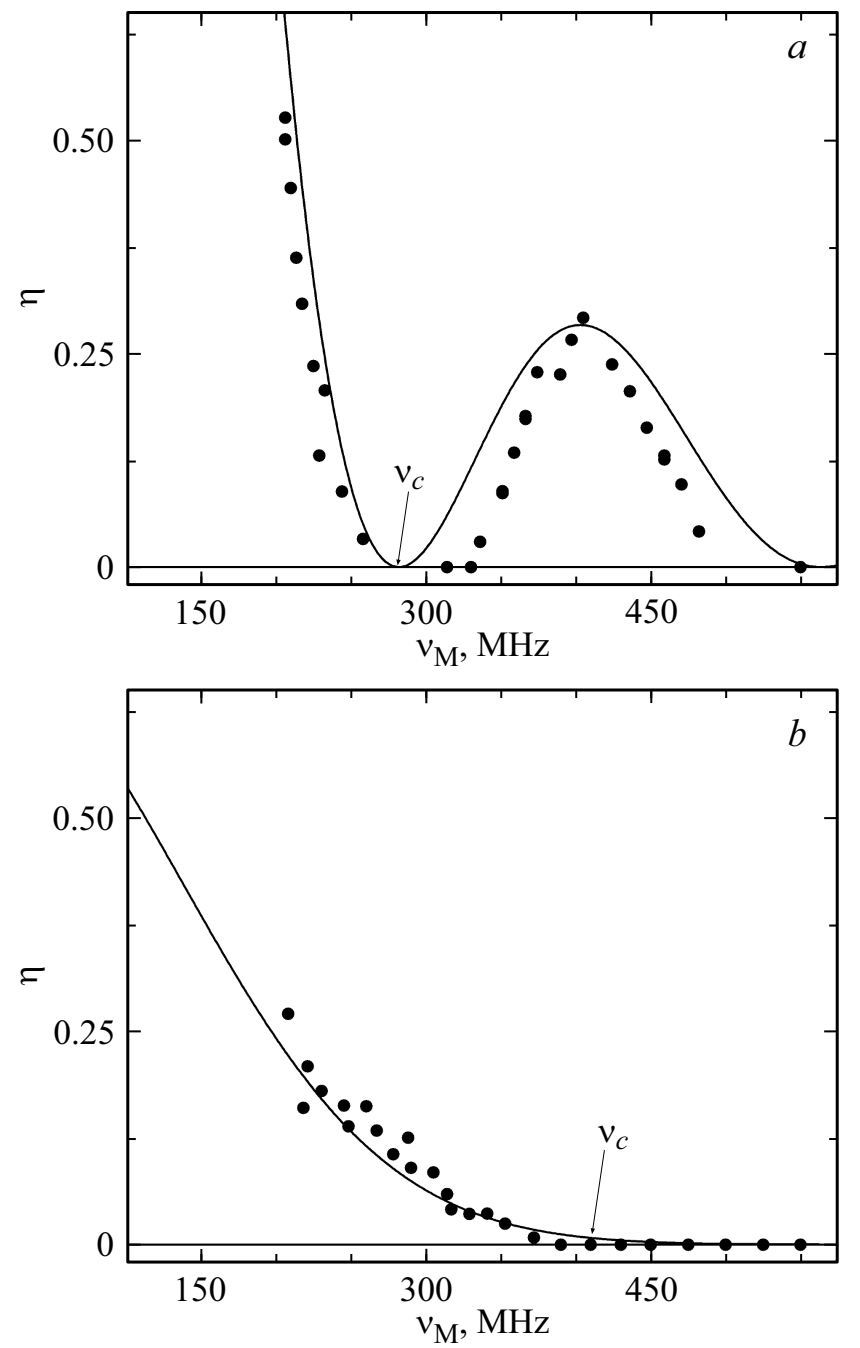

Рис. 5. Зависимость глубины модуляции $\eta$ от частоты ФМР $v_{M}$. Кружки - экспериментальные результаты для образцов ЭПФГ толщиной $10.5(a)$ и $7.6 \mu \mathrm{m}(b)$. Сплошная линия (a) построена с помощью выражения (9), сплошная линия $(b)$ построена для удобства зрительного восприятия.

$\eta=\eta\left(v_{M}\right)$ свидетельствует о том, что распределение амплитуды переменной намагниченности вдоль нормали к образцу не является однородным. В качестве примера на рис. 5, $b$ приведена сплошная линия для амплитуды переменной намагниченности $m=m(z)$, описываемой функцией Гаусса с максимумом при $z=h / 2$. Однако ввиду отсутствия дополнительных оснований для подобного распределения намагниченности, сплошную линию на рис. 5, $b$ можно рассматривать лишь как линию, построенную для удобства зрительного восприятия.

В любом случае, из экспериментально полученных зависимостей $\eta=\eta\left(v_{M}\right)$ можно оценить частоту $v_{c}$, при которой $\eta\left(v_{c}\right)=0$, а из этой критической частоты оценить скорость волны в ферритовой пленке $c_{F}^{(\eta)}$ как $c_{F}^{(\eta)}=v_{c} h$. Соответствующие данные приведены в таблице. 
Будем исходить из того, что как на свободной поверхности пленки, так и на интерфейсе пленка-подложка возможно поверхностное закрепление спинов. В результате этого часть спинов в некоторой области вблизи поверхности не вносит вклад в переменную намагниченность. Если поверхностное закрепление спинов слабо по сравнению с переменным магнитным полем или толщина слоя, в котором следует учитывать поверхностное закрепление, мала по сравнению с толщиной пленки, то в этом случае можно ожидать равномерное по толщине пленки распределение амплитуды переменной намагниченности $m=m(z)$. При этом размер области, в которой возбуждаются упругие колебания за счет магнитоупругих взаимодействий, будет практически совпадать с толщиной магнитной пленки и для зависимости $\eta=\eta\left(v_{M}\right)$ получим зависимость, подобную приведенной на рис. 5, $a$.

В случае сильного закрепления спинов на поверхности амплитуда переменной намагниченности на краях пленки практически равна нулю, а максимум достигается посередине. В этом случае вопрос о конкретном законе, описывающем зависимость $m=m(z)$, остается открытым. Например, можно предположить, что эта зависимость описывается функцией Гаусса. Как следует из данных рис. 5, $b$, такое предположение качественно не противоречит эксперименту. При этом эффективный размер области магнитоупругого взаимодействия может отличаться от толщины магнитной пленки.

Значения скорости поперечной упругой волны $c_{F}^{(\eta)}$, полученные из оценок по критической частоте, дают значения, более близкие к скорости упругой волны в железоиттриевом феррит-гранате $c_{Y I G} \approx 3.85 \cdot 10^{3} \mathrm{~m} / \mathrm{s}[4]$, чем значения $c_{F}^{(\text {res })}$. Тем не менее для всех исследованных образцов $c_{F}^{(\eta)}<c_{Y I G}$, в связи с чем представляется интересным обсудить специфику возбуждения упругих колебаний в условиях ФМР. Частоте ФМР $v_{M}$ соответствует упругая волна с волновым вектором $k=2 \pi v_{M} / c_{F}$. Однако в слабых магнитных полях такие частота и волновой вектор упругой волны лежат вблизи магнитоакустического резонанса [1]. В результате в ферритовой пленке распространяется гибридная квазиупругая волна, скорость распространения которой меньше, чем скорость чисто упругой волны в феррите.

\section{Заключение}

Исследован низкополевой ФМР в эпитаксиальных пленках ферритов гранатов различного состава с анизотропией типа „легкая плоскость“. В спектрах ФМР, полученных путем частотной развертки, для ряда образцов ЭПФГ обнаружена модуляция интенсивности линии ФМР модами поперечных упругих колебаний, возникающих в результате магнитоупругих взаимодействий в магнитной пленке. Показано, что частотный интервал между модами упругих колебаний определяется, в первую очередь, толщиной немагнитной подложки.
Однако благодаря высокой добротности упругой подсистемы гранатов, заметный вклад вносит и магнитная пленка. При этом чем больше полная толщина структуры пленка-подложка, тем меньше частотный интервал между модами упругих колебаний. Это означает, что в качестве резонатора для упругих колебаний выступает структура пленка-подложка как сплошная слоистая среда.

Экспериментально обнаружена зависимость амплитуды модуляции от частоты ФМР, для объяснения которой предложено учитывать распределение амплитуды поперечной намагниченности по толщине пленки $m=m(z)$. Для моды упругих колебаний с волновым вектором $k_{F}$ в ферритовой пленке эффективность магнитоупругого взаимодействия пропорциональна амплитуде гармоники с волновым вектором $k_{F}$ разложения $m=m(z)$ по волновым векторам. При отсутствии поверхностного закрепления спинов в пленке амплитуда модуляции убывает осциллируя. При сильном поверхностном закреплении спинов амплитуда модуляции убывает монотонно. Оценки скорости упругой волны в ферритовой пленке показывают, что наряду с влиянием эффектов поверхностного закрепления спинов и интерфейса пленка-подложка следует учитывать изменение скорости квазиупругой волны в окрестности магнитоакустического резонанса.

\section{Финансирование работы}

Исследование выполнено при финансовой поддержке РФФИ в рамках научного проекта № 18-29-02120.

\section{Конфликт интересов}

Авторы заявляют, что у них нет конфликта интересов.

\section{Список литературы}

[1] В. Штраус. В сб.: Физическая акустика, под ред. У. Мэзона. (Мир, М., 1970), т. 4, с. 247. [Пер с англ.: Physical acoustics. Principles and methods, ed. by W.P. Masson. (Academic Press, NY. and London, 1968), vol. IV, Part B.]

[2] И.В. Бычков, Д.А. Кузьмин, В.Д. Бучельников, В.Г. Шавров. Влияние взаимодействия подсистем на динамические свойства магнетиков (Физматлит, М., 2016)

[3] А.С. Бугаев, Ю.В. Гуляев, П.Е. Зильберман, Ю.А. Филимонов. ФТТ, 23, 2647 (1981).

[4] Ю.В. Гуляев, П.Е. Зильберман, Г.Т. Казаков, В.Г. Сысоев, В.В. Тихонов, Ю.А. Филимонов, Б.П. Нам, А.С. Хе. Письма в ЖЭТФ, 34, 500 (1981).

[5] M. Ye, A. Brockmeyer, P. Wigen, H. Dötsch. J. Phys. Paris, 49, C8-989 (1988).

[6] L. Thevenard, C. Gourdon, J.Y. Prieur, H.J. von Bardeleben, S. Vincent, L. Becerra, L. Largeau, J.-Y. Duquesne. Phys. Rev. B, 90, 094401 (2014). DOI: 10.1103/PhysRevB.90.094401

[7] Ю.В. Гуляев, С.В. Тарасенко, В.Г. Шавров. УФН, 181, 595 (2011).

[8] V.L. Preobrazhensky, V.V. Aleshin, P. Pernod. Wave Motion, 81, 15 (2018). DOI: 10.1016/j.wavemoti.2018.05.002 
[9] В.В. Тихонов, А.Н. Литвиненко, А.В. Садовников, С.А. Никитов. Изв. РАН. Сер. физ., 80, 1389 (2016).

[10] А.С. Бугаев, В.Б. Горский. ФТТ, 44 (4), 724 (2002).

[11] Ю.В. Хивинцев, В.К. Сахаров, С.Л. Высоцкий, Ю.А. Филимонов, А.И. Стогний, С.А. Никитов. ЖТФ, 88 (7), 1060 (2018).

[12] S. Streib, H. Keshtgar, G. Bauer. Phys. Rev. Lett., 121, 027202 (2018).

[13] J. Holanda, D.S. Maior, A. Azevedo, S.M. Rezende. Nat. Phys., 14, 500 (2018). DOI: 10.1038/s41567-018-0079-y

[14] J.J. Nakane, H. Kohno. Phys. Rev. B, 97, 174403 (2018). DOI: 10.1103/PhysRevB.97.174403

[15] K. An, A.N. Litvinenko, R. Kohno, A.A. Fuad, V.V. Naletov, L. Vila, U. Ebels, G. de Loubens, H. Hurdequint, N. Beaulieu, J. Ben Youssef, N. Vukadinovic, G.E.W. Bauer, A.N. Slavin, V.S. Tiberkevich, O. Klein. Phys. Rev. B, 101, 060407 (2020). DOI: 10.1103/PhysRevB.101.060407

[16] П.М. Ветошко, А.К. Звездин, В.А. Скиданов, И.И. Сыворотка, И.М. Сыворотка, В.И. Белотелов. Письма в ЖТФ, 41, 103 (2015).

[17] A.R. Prokopov, P.M. Vetoshko, A.G. Shumilov, A.N. Shaposhnikov, A.N. Kuz'michev, N.N. Koshlyakova, V.N. Berzhansky, A.K. Zvezdin, V.I. Belotelov. J. Alloy. Compd., 671, 403 (2016). http://dx.doi.org/10.1016/j.jallcom. 2016.02.036

[18] С.Н. Полулях, В.Н. Бержанский, Е.Ю. Семук, В.И. Белотелов, П.М. Ветошко, В.В. Попов, А.Н. Шапошников, А.Г. Шумилов, А.И. Чернов. ЖЭТФ, 2021. (принято в печать)

[19] Л.М. Бреховских. Волны в слоистых средах (Наука, М., 1973) 